\title{
Did OPEC change its behaviour after the November 2014 meeting?
}

\author{
Pål Boug ${ }^{1}\left(\mathbb{C} \cdot\right.$ Ådne Cappelen $^{1}$
}

Received: 16 May 2020 / Accepted: 8 July 2021 / Published online: 20 August 2021

(C) The Author(s) 2021

\begin{abstract}
We analyse the behaviour of OPEC as a group by formulating a theoretical model that encompasses the perfect competition model and various forms of the imperfect competition model. By confronting the theoretical model with quarterly data for the period from 1992 to 2013 within the context of a cointegrated vector autoregressive (CVAR) model, we find support for the imperfect competition hypothesis regarding the output decisions of OPEC. We also find that a dynamic equilibrium correction model with imperfect competition is stable in-sample. However, a forecasting exercise for the period from 2014 to 2018 reveals that the model breaks down following the November 2014 meeting at which OPEC decided to keep its supply unchanged despite the huge oil price drop in advance. The model systematically underpredicts OPEC production over the forecast period and by as much as 2.5 million barrels per day at the end of 2016. During 2018, however, the model forecasts OPEC production quite well. Our findings suggest that the behaviour of OPEC did indeed change significantly after the November 2014 meeting.
\end{abstract}

Keywords OPEC behaviour - Economic models · CVAR - Dynamic forecasting JEL Classification C51 · C52 - D43

\section{Introduction}

The growing importance of OPEC during the 1970s and the increased perception that the organisation could affect world oil prices initiated a lot of empirical work about the oil market, and in particular, about the behaviour of OPEC. Yet, there is no clear consensus in the literature on the exact nature of the behaviour of OPEC and its ability to influence world oil prices. Some studies rely on a competitive model, while others

\footnotetext{
$凶 \quad$ Pål Boug

pal.boug@ssb.no

1 Research Department, Statistics Norway, P.O.B. 2633 St. Hanshaugen, Oslo 0131, Norway
} 
specify models of imperfect competition, often assuming that OPEC functions like a monopoly, an oligopoly or a cartel in some way; see, for example, Smith (2009), Almoguera et al. (2011), Fattouh and Mahadeva (2013) and Alkhathlan et al. (2014) for reviews of the literature.

The study of Griffin (1985), which inter alia tests the various cartel models and the competitive model for the period 1971 to 1983 , is the starting point for much of the empirical work in this field of research. Among the various competing hypotheses about OPEC behaviour, Griffin (1985) finds some support for a cartel model where OPEC as a group is a dominant producer setting the oil price, while non-OPEC countries behave as a competitive fringe. A similar conclusion is reached in Bckem (2004), relying on data for the 1990s. Other studies find that a core group within OPEC, or even Saudi Arabia alone, fits the description of a dominant producer; see, for example, Dahl and Yücel (1991), Alhajji and Huettner (2000a, b) and Hansen and Lindholt (2008). Another study by Almoguera et al. (2011) concludes that the behaviour of OPEC over the period from 1974 to 2004 is best described as a Cournot competition with a competitive fringe. Recently, Golombek et al. (2018) find support for a dominant firm-competitive fringe model, in which both the demand and the supply side of the oil market are taken into account, using data over the period from 1986 to 2016. Smith (2005) argues for a model of the OPEC countries as a "bureaucratic production syndicate" and finds strong evidence of collusion, but with significant transaction costs regarding redistribution of output among members of the cartel. By contrast, Spilimbergo (2001) finds no support for the hypothesis that OPEC is a market sharing cartel and Okullo and Reynès (2016) show that heterogeneity within OPEC and non-OPEC supply create strong incentives against collusion.

The empirical evidence on OPEC behaviour is thus rather mixed. Kaufmann et al. (2008) argue that the failure to agree on a benchmark model is not a weakness, but rather a strength, as OPEC behaviour does not fit easily into any single model. The disagreement and plethora of models may be due to changing OPEC behaviour over time, as pointed out by Almoguera et al. (2011), Fattouh and Mahadeva (2013) and Alkhathlan et al. (2014). Several oil market analysts have also argued that at the November 2014 meeting, OPEC significantly changed its behaviour by deciding to keep its supply unchanged despite the huge oil price drop in advance. Recently, Behar and Ritz (2016) argue that this decision was taken by OPEC mainly to limit the role of competitors like American producers of shale oil.

In this paper, we contribute to the literature by studying the behaviour of OPEC as a group for the period from 1992 to 2018, with a special focus on the possibility of changes in actions taken by the organisation before and after the November 2014 meeting. First, we set up a theoretical model of OPEC behaviour that encompasses several of the possibilities discussed in the literature, among them the competitive model and various forms of the imperfect competition model. Unlike some related empirical studies, our model includes a possible role for resource stock to affect OPEC extraction or production costs. Then, in the empirical analysis, we contribute to the literature by paying particular attention to time series properties of variables involved and searching for statistically well-specified underlying models as premises for valid inference about the OPEC behaviour. 
By estimating a CVAR model based on data running from the first quarter of 1992 to the fourth quarter of 2013, we find support for the imperfect competition hypothesis regarding the output decisions of OPEC. The implied average estimate of the price elasticity of demand for OPEC oil is less than minus unity, consistent with the dominant producer model. Moreover, OPEC's oil reserves seem to affect production costs positively, implying support for the Arrow (1962) learning by doing hypothesis. We also find that a dynamic equilibrium correction model with imperfect competition is reasonably stable in-sample. However, a forecasting exercise based on data running from the first quarter of 2014 to the fourth quarter of 2018 reveals that the model breaks down following the OPEC meeting in November 2014. The model systematically underpredicts OPEC production over the forecast period and by as much as 2.5 million barrels per day at the end of 2016. A sequence of parameter constancy forecast Chow tests also reveals a significant structural break around the fourth quarter of 2014. During 2018, however, the model forecasts OPEC production quite well. We therefore conclude that the behaviour of OPEC did indeed change significantly after the November 2014 meeting. Behar and Ritz (2016) also conclude, using a calibrated equilibrium model of the oil market, that OPEC switched from an accommodation strategy up to 2014 to a market share strategy thereafter.

The rest of the paper is organised as follows: Sect. 2 outlines the theoretical framework used for estimation purposes, Sect. 3 describes the data, Sect. 4 reports findings from the cointegration analysis and Sects. 5 and 6 evaluate the empirical performance of the dynamic model of OPEC behaviour in-sample and out-of-sample, respectively. Section 7 provides a conclusion.

\section{Theoretical framework}

Our theoretical framework of the encompassing model of OPEC behaviour builds on Berg et al. (1997) and Boug et al. (2016). We thus start out by assuming an inverse demand function, that OPEC faces as a cartel, of the form

$$
P_{t}=\delta_{0} X_{t}^{\varepsilon}
$$

where $P_{t}$ is the nominal crude oil price per barrel in period $t, X_{t}$ is the supply of OPEC measured in million barrels per day in period $t, \delta_{0}$ are other factors than the oil price affecting demand, and $\varepsilon$ is the constant inverse price elasticity, where $-1<\varepsilon<0$. OPEC has oil reserves at the beginning of period $t, R_{t}$, that is exploited in every period by extraction or production, such that ${ }^{1}$

$$
R_{t+1}=R_{t}-X_{t}
$$

The unit cost function of OPEC's production in period $t, C_{t}$, depends on the oil reserves, such that

$$
C_{t}=c_{0} e^{-\eta R_{t}},
$$

\footnotetext{
${ }^{1}$ Note that we simplify matters by not including additions to stocks in (2) due to new discoveries.
} 
where $c_{0}$ incorporates factor prices and $\eta \lessgtr 0$ depending on the hypothesis about how reserves affect production costs. One such hypothesis is that costs of extraction are higher with fewer reserves $(\eta>0)$. Thus, higher extraction today increases costs tomorrow and in this sense, there are increasing marginal costs in output. Another hypothesis is based on Arrow (1962) learning by doing theory. Combining (2) and (3), the cost function can be expressed as depending on accumulated output $\left(R_{0}-\right.$ $\left.\sum X_{t-1-i}\right)$. Letting the initial reserves, $R_{0}$, be included in the constant term, unit costs depend only on accumulated output. Learning by doing is a simple way of introducing endogenous technological change by assuming $\eta<0$ so that unit costs fall as accumulated output increases. In this case, access to the reserves and exploiting it make it more valuable over time.

OPEC is assumed to maximise the present value of the net income, $N I$, from its crude reserves taking the supply from other producers (the "fringe") as given. NI is defined by

$$
N I=\sum_{t=0}^{\infty}\left(P_{t}-C_{t}\right) X_{t}(1+i)^{-t}
$$

where $i$ is the interest rate assumed constant. $N I$ is maximised subject to (1), (2) and (3). The Lagrangian of this intertemporal problem is thus

$$
L=\sum_{t=0}^{\infty}\left[\left(P_{t}-C_{t}\right) X_{t}(1+i)^{-t}+\lambda_{t+1}\left(R_{t}-X_{t}-R_{t+1}\right)\right],
$$

where $\lambda$ is the Lagrange multiplier, which tells us how much the net present value of $N I$ increases if the resource constraint is relaxed. The first-order condition with respect to $X_{t}$ (for $t=0,1, \ldots, \infty$ ) can be written as

$$
\lambda_{t+1}=\left[(1+\varepsilon) P_{t}-C_{t}\right](1+i)^{-t} .
$$

Note the difference compared to the simpler static condition saying that the oil price is a mark-up over marginal costs, which would imply that the term inside the square brackets in (6) equals zero. ${ }^{2}$ The first-order condition with respect to $R_{t}$ is somewhat more complicated since $R_{t}$ enters in two terms in the last part of the sum in (5). After rearranging, we have (for $t=1, \ldots, \infty$ )

$$
\lambda_{t+1}-\lambda_{t}=-\eta C_{t} X_{t}(1+i)^{-t}
$$

which shows the time path of the Lagrangian or the shadow cost of the resource constraint. This condition does not apply for $t=0$, as $R_{0}$ is exogenous. Initial reserves are given by nature and thus not a choice variable. We see from (7) that $\lambda$ is falling over time when $\eta>0$ since the term on the right-hand side is negative in this case.

\footnotetext{
2 In this case, the mark-up is $(1+\varepsilon)^{-1}$ or $e /(1+e)^{-1}$ when $e$ is the standard price elasticity of demand and $e=\varepsilon^{-1}$. 
This implies that the scarcity rent of resources is increasing over time. If reserves do not enter the unit cost function, the change in $\lambda$ is zero according to (7). This will be zero as long as the resource constraint is not binding, which means that we have the standard mark-up pricing formula.

Using (6) and (7) to eliminate $\lambda$, we obtain

$$
\left[(1+\varepsilon) P_{t}-C_{t}\right]-\left[(1+\varepsilon) P_{t-1}-C_{t-1}\right](1+i)=-\eta C_{t} X_{t},
$$

which, depending on the parameter estimates of $\eta$ and $\varepsilon$, encompasses the following hypotheses about the behaviour of OPEC and the crude oil market structure:

(a) If both $\eta=0$ and $\varepsilon=0$, then $P_{t}-C_{t}=\left(P_{t-1}-C_{t-1}\right)(1+i)$. This is the generalised Hotelling rule stating that "..., the royalty, or the price net of the cost of extracting the marginal unit of the resource, will grow at the interest rate $i$. .; see Devarajan and Fisher (1981). When extraction costs are negligible, this rule will approach what is often stated as the basic Hotelling rule where the price itself grows at the interest rate $i$.

(b) If only $\varepsilon=0$, but $\eta>0$, then it follows as noted earlier from (7) that the scarcity rent or royalty of resources is falling over time due to the increase in cost caused by adding to the stock of cumulative production. This possibility was already noted and discussed in Hotelling (1931). Our model implies price taking behaviour in the crude oil market when $\varepsilon=0$.

(c) If $\eta=0$, but $-1<\varepsilon<0$, then it is the marginal revenue net of the cost of extraction and not the price itself that will grow at the interest rate $i$. Hotelling (1931) also discussed this case and suggested that monopoly power would restrict output and thus lead to a higher price and rent. Our model allows for an arbitrary sign of $\eta$ alongside the restriction $-1<\varepsilon<0$.

Finally, by solving (8) for $X_{t}$ and letting $C_{t}=\left(1+c_{t}\right) C_{t-1}$, where $c_{t}$ is the growth rate in unit costs in period $t$, we get

$$
X_{t}=\frac{1}{\eta}-\frac{(1+i)}{\eta\left(1+c_{t}\right)}-\frac{1+\varepsilon}{\eta}\left[\frac{P_{t}}{C_{t}}-\frac{(1+i)}{\left(1+c_{t}\right)} \frac{P_{t-1}}{C_{t-1}}\right],
$$

which serves as a point of departure for the cointegration analysis in this paper. Our main empirical objective is thus to estimate $\eta$ and $\varepsilon$, the long-run parameters of interest, by means of a CVAR model and available data for $X_{t}, P_{t}, C_{t}$ and $i$. We note that (9) is not a reduced form of a complete model of the crude oil market, but rather an equilibrium model of OPEC's supply decision considering how its policy affects the crude oil price. The choice variable is how much crude to extract and not the oil price itself. While OPEC during parts of the 1970s and the first part of the 1980s stated a reference price, the organisation has in recent decades mainly adhered to a production quota system among the members countries. Since our choice of the starting year of the sample period does not include the period where OPEC operated with a target price, but rather a quota system, we think on a priori grounds that the supply model presented here is a possible approximation worthwhile of empirical investigations. Our choice of using a CVAR is dictated by the theoretical setup of equilibrium conditions and by 
the need to consider the possibility of several cointegrating or long-run relationships between prices, costs and volumes in the crude oil market. In addition, the CVAR is a more general approach to handle non-stationary data than first on a priori grounds differencing the observations to make them stationary and suitable for using standard estimation techniques; see, for example, Juselius (2006, 2015, 2019). The CVAR approach is particularly suitable for our purposes since it combines differences of variables with cointegration among them so as to enabling a study of both long-run and short-run effects within the same model.

We end this section by briefly illustrating how (9) can be consistent with the dominant producer model of OPEC behaviour. As mentioned in the introduction, that model has been studied by Griffin (1985), Dahl and Yücel (1991), Alhajji and Huettner (2000a, b), Bckem (2004), Hansen and Lindholt (2008) and Golombek et al. (2018) among others. Typically, the dominant producer model involves assuming that OPEC as a cartel collectively sets the oil price when marginal revenues equal marginal costs. Non-OPEC producers or the competitive fringe will then supply oil when marginal costs equal the oil price. The demand for OPEC oil or "call on OPEC" is given by the residual demand, which is total demand for oil in the world less supply of oil by the fringe. Assuming a standard world demand function depending on the consumer price of oil, while the supply of non-OPEC producers depends positively on the producer price of oil, the price elasticity of demand for OPEC oil, $e_{O P E C}$, can be expressed as ${ }^{3}$

$$
\varepsilon^{-1}=e_{O P E C}=e_{W} M S O P E C^{-1}-s\left(M S O P E C^{-1}-1\right),
$$

where $e_{W}<0$ is the price elasticity of world oil demand, $s>0$ is the supply elasticity of the fringe, and MSOPEC is the market share of OPEC in the world oil market. The price elasticity in (1) is then simply the inverse of the elasticity in (10). In this sense, $\varepsilon$ is not a single structural parameter, but rather a combination of such parameters. Because the market share of OPEC is changing over time, $\varepsilon$ is also a time-varying parameter in (10). As pointed out by Alhajji and Huettner (2000a), (10) accommodates the dominant producer model if the profit maximising OPEC operates on the elastic part of its demand curve, that is when $e_{O P E C}<-1 .{ }^{4}$ Under the assumption that $-1<\varepsilon<0$, we see that (9) can be consistent with the dominant producer model of OPEC behaviour. That said, our model can only be consistent with this model as neither OPEC's residual demand nor the price setting rule as such are explicit parts of (9) in the empirical analysis.

\footnotetext{
${ }^{3}$ See Alhajji and Huettner (2000a). Consider world demand for oil, $X_{W}=a P^{e} W$, where other factors than the oil price affecting demand are included in the parameter $a$, and non-OPEC supply of oil, $X_{N O}=b P^{s}$, where other factors than the oil price affecting supply are captured by the parameter $b$. The "call on OPEC" is $X=X_{W}-X_{N O}=a P^{e} W-b P^{s}$ and the market share of OPEC is MSOPEC $=X / X_{W}$. The expression in (10) is then found by differentiating $\log (X)$ with respect to $\log (P)$.

${ }^{4}$ Otherwise, the profit maximisation condition, saying that the oil price equals marginal cost times a mark-up, is rejected because the oil price becomes negative.
} 


\section{Description of data}

OPEC was founded in Baghdad with the signing of an agreement in September 1960 by the five countries Islamic Republic of Iran, Iraq, Kuwait, Saudi Arabia and Venezuela. These countries were later joined by Qatar (1961), Indonesia (1962), Libya (1962), the United Arab Emirates (1967), Algeria (1969), Nigeria (1971), Ecuador (1973), Gabon (1975), Angola (2007), Equatorial Guinea (2017) and Congo (2018). Ecuador suspended its membership in December 1992, rejoined OPEC in October 2007, but decided to withdraw its membership again in January 2020. Indonesia suspended its membership in January 2009, reactivated it again in January 2016, but decided to suspend its membership once more in November 2016. Gabon terminated its membership in January 1995, but rejoined OPEC in July 2016, while Qatar terminated its membership in January 2019. Hence, OPEC has currently a total of thirteen member countries. Our empirical analysis is based on all the OPEC member countries at various points in time during the sample period.

The history of OPEC shows that its behaviour has varied over time due to inter alia changing market conditions and new oil producers entering the oil market. ${ }^{5}$ The previously mentioned quota system, which is still in operation today, was formally established by OPEC in 1982 in order to coordinate production decisions by the member countries. Our model thus implicitly assumes that OPEC members coordinate their production decisions in some way. However, there are some episodes of wars and conflicts between the member countries after the introduction of the quota system where coordination does not seem to be a reasonable assumption. The Iraq-Kuwait war in 1990 and the following US invasion of Iraq in January 1991 are such episodes where it is hard to justify coordination within OPEC, at least for Iraq and Kuwait. ${ }^{6}$

For this reason, the empirical analysis is based on quarterly, seasonally unadjusted data that span the period $1992 q 1-2018 q 4$, of which data for the period $1992 q 1-$ $2013 q 4$ and $2014 q 1-2018 q 4$ are used for estimation and out-of-sample forecasting, respectively. Because OPEC members have not always been sticking to their quotas in absence of conflicts, we use recursive methods to investigate whether our estimated models are stable in-sample. We extend the estimation sample by twenty quarters for forecasting to shed light on any change in the behaviour of OPEC before and after the November 2014 meeting.

Figure 1 displays quarterly time series of OPEC crude oil production including lease condensate $\left(X_{t}\right)$ measured in million barrels per day, OPEC reference basket spot oil price per barrel $\left(P_{t}\right)$ measured in US dollars, OPEC supply costs per barrel $\left(C_{t}\right)$ measured in US dollars and the US (annualised) ten-year bond yield $\left(i_{t}\right)$, which is used as the interest rate in the empirical analysis. ${ }^{7}$ We clearly see that the production

\footnotetext{
5 See Fattouh and Mahadeva (2013) for a brief history of OPEC.

6 Some studies suggest that Saudi Arabia has acted as a swing producer by stabilising the supply of OPEC, particularly in episodes of supply disruptions due to conflicts and wars in the region; see, for example, Nakov and Nuño (2013) and Alkhathlan et al. (2014). We discuss this issue further in Sect. 4.

7 Quarterly time series of crude oil production is downloaded from the web site of EIA, https://www. eia.gov/opendata/qb.php?sdid=INTL.57-1-OPEC-TBPD.Q, and monthly time series of the OPEC reference basket oil price, which is made quarterly as three months averages, is downloaded from the web site of OPEC, https://asb.opec.org/data/ASB_Data.php (Table 7.1). The time series of supply costs for
} 

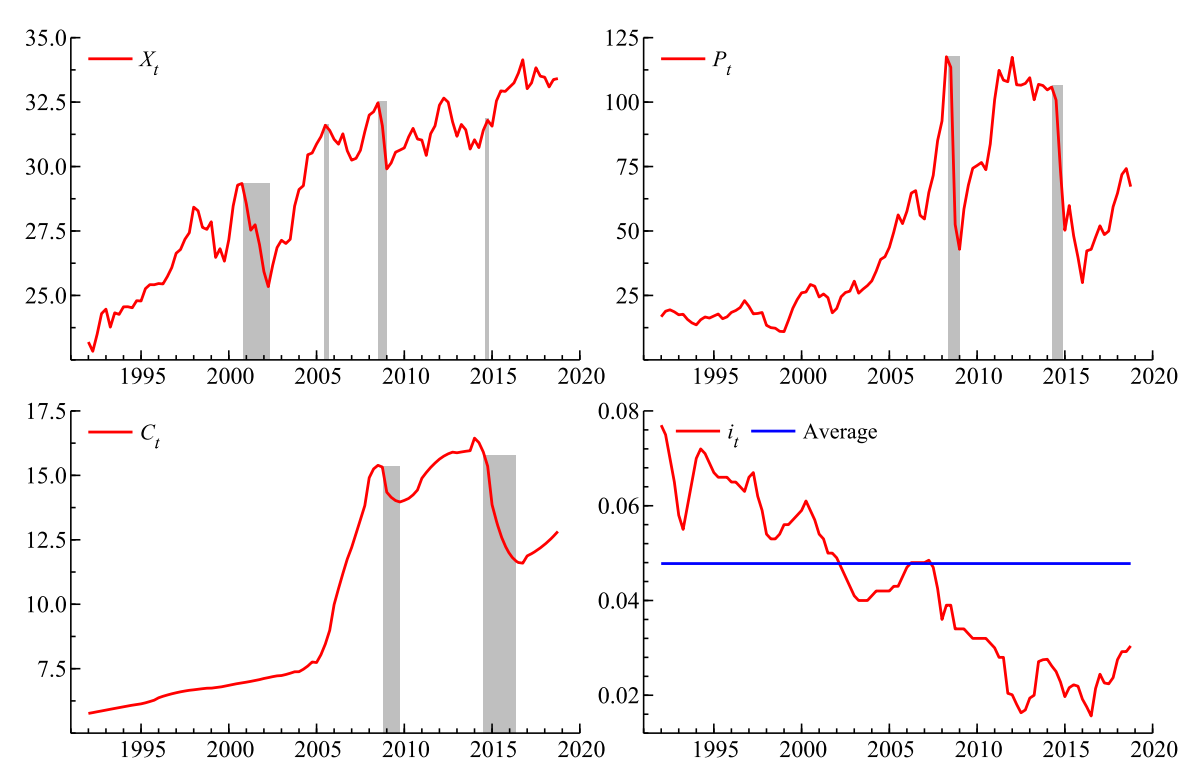

Fig. 1 Time series of OPEC production $\left(X_{t}\right)$, OPEC reference basket oil price $\left(P_{t}\right)$, OPEC supply costs $\left(C_{t}\right)$ and US ten-year bond yield $\left(i_{t}\right)$. Sample period: $1992 q 1-2018 q 4$. Sources: EIA $\left(X_{t}\right)$, OPEC $\left(P_{t}\right)$, Hansen and Lindholt (2008) and IHS Markit $\left(C_{t}\right)$ and Macrobond $\left(i_{t}\right)$

of OPEC, with some significant exceptions, has increased steadily from around 23.5 million barrels per day on average in 1992 to around 33.5 million barrels per day on average in 2018. The supply of OPEC fell considerably through 2001 and the first half of 2002 alongside the international economic downturn before gradually picking up and reaching a high historical level of around 31.5 million barrels per day in the mid of 2005 .

The development in OPEC production coincides periodically rather closely with the development in the oil price, presumably because the output is held back or reduced by OPEC to maintain or increase the oil price. For instance, OPEC reduced its production by somewhat more than 2 million barrels per day following the huge drop in the oil price from around 145 US dollars per barrel by July 2008 to below 40 US dollars per barrel at the end of 2008; see Smith (2009). Surprisingly enough, however, OPEC decided not to cut its production on the November 2014 meeting despite the huge drop in the oil price in advance. In the aftermath of that meeting the oil price continued to fall to around 40 US dollars per barrel at the end of 2015 and further to below

Footnote 7 continued

the period from 1992 to 2001 is based on an average of the lower and upper bounds of OPEC supply costs data applied in Hansen and Lindholt (2008). The supply costs used in Hansen and Lindholt (2008) include the finding, the development and the production costs. For details about data sources and construction of the supply costs, see Hansen and Lindholt (2008, Sect. 3 and Appendix A). The time series of supply costs is extended by means of the IHS Markit upstream capital and operating cost index, downloaded from https:// ihsmarkit.com/info/cera/ihsindexes/index.html, in order to cover the period from 2001 to 2018 . The time series of the US ten year bond yield is acquired from Macrobond. The data set used in this paper as well as a detailed description of how the various time series are constructed is available from the authors upon request. 

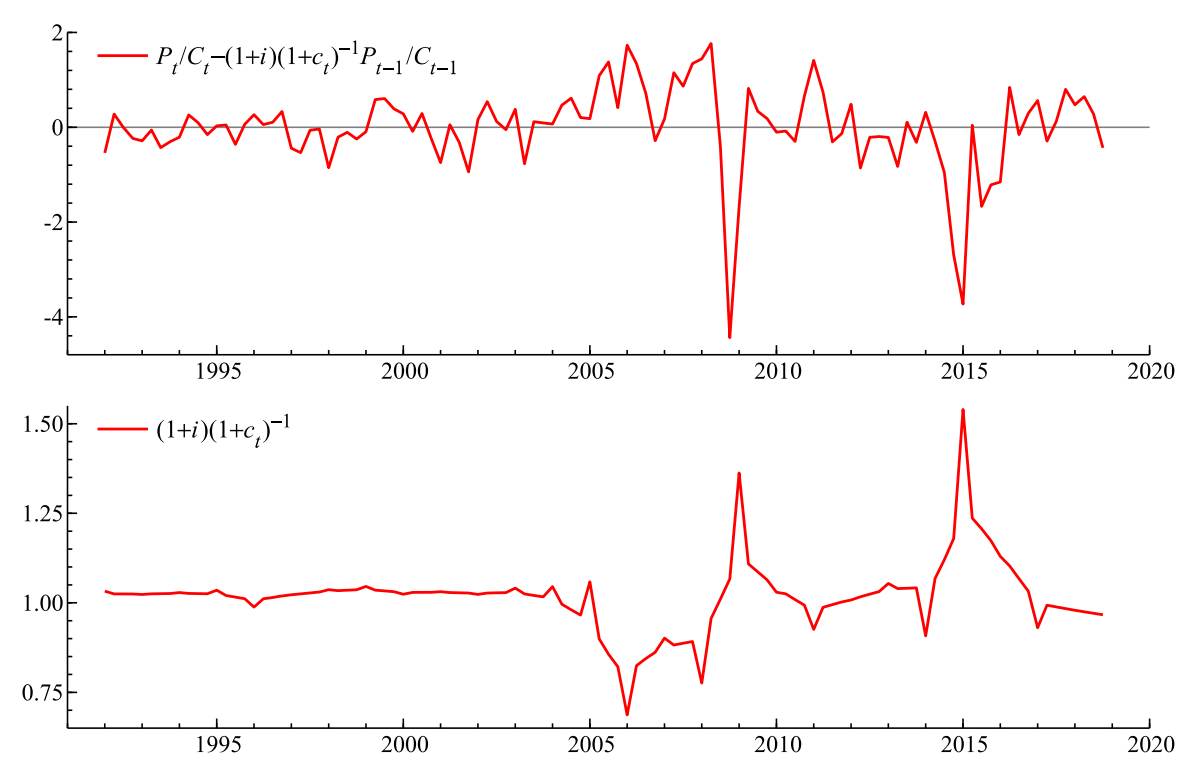

Fig. 2 Time series of composite variables in (9). Sample period: $1992 q 1-2018 q 4$. Sources: OPEC $\left(P_{t}\right)$, Hansen and Lindholt (2008) and IHS Markit $\left(C_{t}\right)$ and Macrobond $(i)$

30 US dollars per barrel in January 2016. As noted in the introduction, we may see this as evidence of OPEC having changed significantly its behaviour to reduce supply of competitors like American producers of shale oil. Rather than cut production to increase the price, OPEC chose to engage in a price war with these producers given that the extraction costs of OPEC are much lower than those for the shale producers. ${ }^{8}$

The development in the supply costs of OPEC is also much in line with the development in the oil price through the most parts of the sample period. Except from a drop of around 10 per cent in the wake of the financial crisis in 2008, the supply costs of OPEC increased steadily from about 6 US dollars per barrel on average in 1992 to about 16 US dollars per barrel on average in 2014. From the second quarter of 2014 to the first quarter of 2016, OPEC reduced its supply costs considerably by somewhat more than 25 per cent, probably to meet the huge fall in the oil price in the same period to maintain its oil income. We also see from Fig. 1 that the supply costs are generally much lower than the oil price, also in low-price periods. As such, OPEC has a competitive advantage in the oil market as other producers of oil typically have much higher production costs. Finally, the US ten-year bond yield has fallen steadily from around 7 per cent on average in 1992 to around 3 per cent on average in 2018. The sample period average of the interest rate, which is used in the empirical analysis of (9), equals 4.8 per cent.

We now briefly turn to time series properties. Figure 2 depicts time series of the two composite variables, $(1+i)\left(1+c_{t}\right)^{-1}$ and $\left[P_{t} / C_{t}-(1+i)\left(1+c_{t}\right)^{-1} P_{t-1} / C_{t-1}\right]$, in (9). Because the US ten-year bond yield is annualised per definition, $C_{t} / C_{t-1}$ is annualised

\footnotetext{
8 See, for example, https://www.reuters.com/article/us-opec-meeting-shale/inside-opec-room-naimideclares-price-war-on-u-s-shale-oil-idUSKCNOJC1GK20141128.
} 
to measure the variable $(1+i)\left(1+c_{t}\right)^{-1}$ on the same frequency both in the nominator and in the denominator. The spikes in $(1+i)\left(1+c_{t}\right)^{-1}$ around 2008-2009 and 20152016 are attributed to the above-mentioned drop in OPEC supply costs during these years. Augmented Dickey-Fuller tests indicate a clear unit root in $X_{t}$. We thus regard OPEC production to be a non-stationary $I(1)$ variable. The two composite variables, on the other hand, are not so clear-cut with respect to time series properties as augmented Dickey-Fuller tests reveal that these variables may be regarded as borderline cases as either $I(0)$ or $I(1)$ variables. ${ }^{9}$ We shall nevertheless assume that a reduced rank VAR model in line with (9) is relevant as an empirical model. The issue of cointegration is formally tested for in the next section.

\section{Cointegration analysis}

Because multiple long-run relationships may exist among the variables included in the theoretical model of the OPEC behaviour, we employ the (Johansen 1995, p. 167 ) trace test for cointegration rank determination. We thus start with an unrestricted $p$-dimensional VAR of order $k$ of the form

$$
Y_{t}=\sum_{i=1}^{k} \Pi_{i} Y_{t-i}+\mu+\delta t+\epsilon_{t}, t=k+1, \ldots, T
$$

where $Y_{t}=\left(Y_{1, t}, Y_{2, t}, Y_{3, t}\right)^{\prime}, Y_{1, t}=X_{t}, Y_{2, t}=\left[P_{t} / C_{t}-(1+i)\left(1+c_{t}\right)^{-1} P_{t-1} / C_{t-1}\right]$, $Y_{3, t}=(1+i)\left(1+c_{t}\right)^{-1}, \mu$ represents constants and seasonals $\left(S D_{1 t}, S D_{2 t}\right.$ and $\left.S D_{3 t}\right), \delta$ is a coefficient vector of a linear deterministic trend $t, \Pi_{1}, \ldots, \Pi_{k}$ are coefficient matrices of lagged level variables, $\epsilon_{k+1}, \ldots, \epsilon_{T}$ are independent Gaussian innovations with expectation zero and covariance matrix $\Omega$, and $T$ is the total number of observations. The initial observations $Y_{1}, \ldots, Y_{k}$ are kept fixed.

The question now is how (11) can be reparameterised to a CVAR in which the OPEC behaviour can be formulated as a reduced rank restriction on the impact matrix $\Pi=-\left(I-\Pi_{1}-\ldots-\Pi_{k}\right)$. When $Y_{t}$ is $I(1)$, the first difference $\Delta Y_{t}$ is $I(0)$, implying either $\Pi=0$ or $\Pi$ has reduced rank, such that $\Pi=\alpha \beta^{\prime}$, where $\alpha$ and $\beta$ are (3x $r$ ) matrices of adjustment coefficients and long-run parameters, respectively, $0<r<3$, and $r$ denotes the rank order of $\Pi$. A preliminary analysis of $\Pi=\alpha \beta^{\prime}$ by means of the trace test, using (11) as the underlying model with different lag order $(k=2, \ldots, 5)$, shows that there exists one and only one cointegrating relationship between $Y_{1, t}$, $Y_{2, t}$ and $Y_{3, t}$ at the 5 per cent significance level. Testing a zero restriction on the adjustment coefficient of $Y_{3, t}$ by a standard likelihood ratio test under the assumption of $r=1$ provides strong evidence that $Y_{3, t}$ is weakly exogenous for the cointegrating parameters. We are therefore motivated to follow Harbo et al. (1998) and move on to a partial VAR by conditioning on $Y_{3, t}$ without loss of information in the successive analysis.

\footnotetext{
9 Results from the augmented Dickey-Fuller tests and other test results commented upon, but not reported by tables or figures to save space in Sects. 4, 5 and 6, are available from the authors upon request.
} 
Table 1 Tests for cointegration rank

\begin{tabular}{llll}
\hline$r$ & $\lambda_{i}$ & $\lambda_{\text {trace }}$ & $5 \%$ Harbo \\
\hline$r=0$ & 0.395 & 50.144 & 30.5 \\
$r \leq 1$ & 0.065 & 5.915 & 15.2 \\
\hline
\end{tabular}

Sample period: $1992 q 1-2013 q 4$. The underlying partial VAR is of order 3 with $Y_{t}=\left(Y_{1, t}, Y_{2, t}\right)^{\prime}, Y_{3, t}$ as a conditioning variable, a linear trend as a restricted variable and constants, seasonals dummies $\left(S D_{1 t}, S D_{2 t}\right.$ and $S D_{3 t}$ ) and a dummy variable $(D 08 q 4)$ which equals one in $2008 q 4$, otherwise zero, as unrestricted deterministic terms. $r$ denotes the rank order of $\Pi=\alpha \beta^{\prime}, \lambda_{i}$ are the eigenvalues from the reduced rank regressions, $\lambda_{\text {trace }}$ are the trace test statistics, and $5 \%$ Harbo are the critical values $(5$ per cent significance level) from Table 2 in Harbo et al. (1998)

Table 2 Likelihood ratio tests of the OPEC behaviour

\begin{tabular}{lll}
\hline Hypothesis & LR tests & $p$-values \\
\hline$\alpha_{1}=0$ & $\chi^{2}(1)=10.70$ & 0.001 \\
$\alpha_{2}=0$ & $\chi^{2}(1)=32.36$ & 0.000 \\
$\beta_{1}=0$ & $\chi^{2}(1)=3.93$ & 0.047 \\
$\beta_{2}=0$ & $\chi^{2}(1)=39.43$ & 0.000 \\
$\beta_{3}=0$ & $\chi^{2}(1)=18.39$ & 0.000 \\
\hline
\end{tabular}

Sample period: $1992 q 1-2013 q 4$. The likelihood ratio (LR) tests with degrees of freedom in parentheses are based on the partial CVAR with $r=1$ and without a linear trend. The exclusion test of $Y_{1, t}$ is based on normalising on $Y_{3, t}$, whereas the exclusion tests of $Y_{2, t}$ and $Y_{3, t}$ are based on normalising on $Y_{1, t}$

According to both Akaike's information criterion (AIC), likelihood ratio tests of sequential model reduction and diagnostic tests of the residuals, the partial VAR in our case should include three lags $(k=3)$ as the premise for the cointegration analysis. We note that no impulse dummies other than one in the fourth quarter of 2008 to mop up the huge drop in the oil price during the financial crisis of around 110 dollars per barrel are needed to obtain a well-specified partial system. Table 1 reports trace test statistics for the partial VAR assuming $k=3$.

We see that the null hypothesis of no cointegration can be rejected, whereas the hypothesis of at most one cointegrating relationship between $Y_{1, t}, Y_{2, t}$ and $Y_{3, t}$ cannot be rejected at the 5 per cent significance level. Assuming the rank to be unity, a likelihood ratio test of model reduction from a partial CVAR with the linear trend to a partial CVAR without the linear trend $(\delta=0)$ yields $\chi^{2}(1)=0.25$ with a $p$-value of 0.62 . The linear trend is thus insignificant and excluded from the reduced rank partial VAR when testing the OPEC behaviour further based on the economic model in (9). Table 2 reports likelihood ratio tests of $\alpha=\left(\alpha_{1}, \alpha_{2}\right)^{\prime}$ and $\beta=\left(\beta_{1}, \beta_{2}, \beta_{3}\right)^{\prime}$ assuming $r=1$.

First, we observe that weak exogeneity of both $Y_{1, t}$ and $Y_{2, t}$ for the long-run parameters, in contrast to $Y_{3, t}$, is rejected. Also, the likelihood ratio tests reject the hypothesis that the modelled variables $Y_{1, t}$ and $Y_{2, t}$ as well as the conditional variable $Y_{3, t}$ are excluded from $\beta$. Hence, we obtain the following unrestricted cointegrating vector (normalised on OPEC production) 

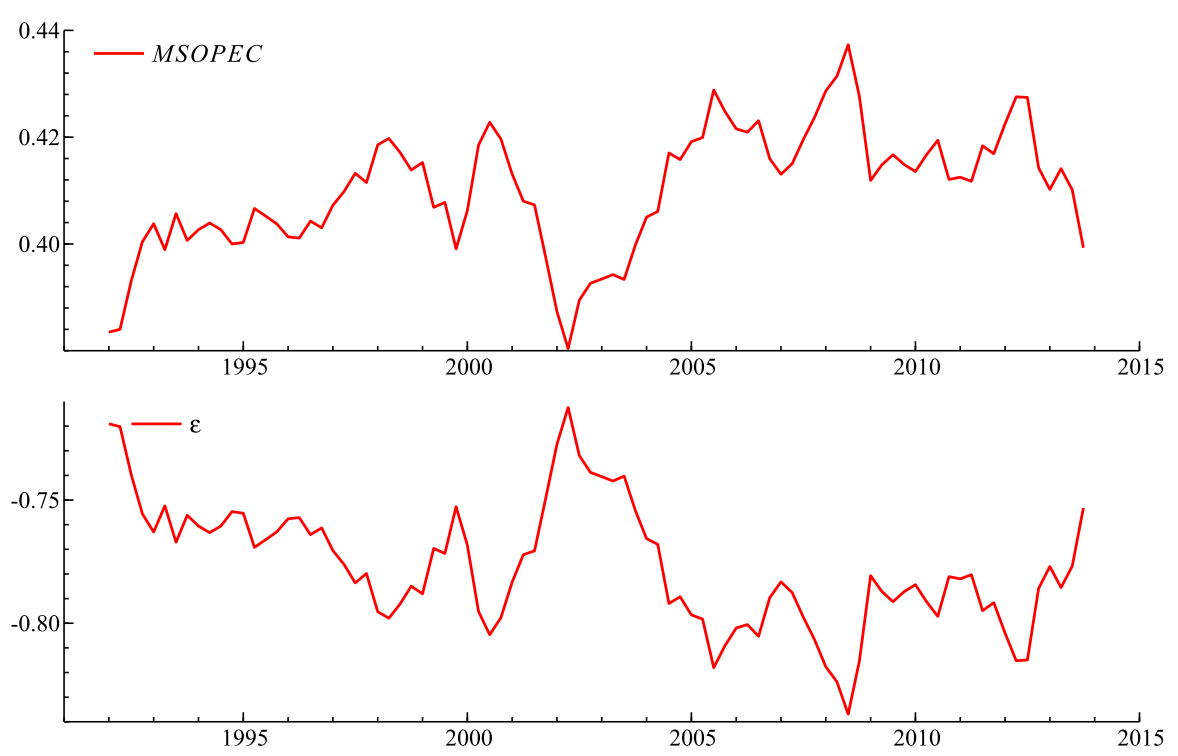

Fig. 3 OPEC's market share (MSOPEC) and time-varying $\varepsilon$. Sample period: $1992 q 1-2013 q 4$. The calculation of $\varepsilon$ is based on (10), $e_{W}=-0.41, s=0.2$ and time-varying MSOPEC, which is defined as $X_{t} / X_{W, t}$, where $X_{W, t}$ is world crude oil production. Source: EIA $\left(X_{t}, X_{W, t}\right)$

$$
Y_{1, t}=\text { const. }+\underset{(5.4448)}{35.326 Y_{2, t}}+\underset{(38.271)}{161.470 Y_{3, t}},
$$

with estimated standard errors in parentheses. The associated vector of adjustment coefficients is $\widehat{\alpha}=(-0.017,0.029)^{\prime}$ with corresponding $t$-values equal to -3.17 and 5.87 , respectively. Because any deviations from (12) are also significantly corrected through the adjustment of OPEC production, we regard the estimated cointegrating vector as a long-run relationship of OPEC behaviour consistent with the economic model in (9). Besides, a plot of $\widehat{e q c m}_{t}=Y_{1, t}-35.326 Y_{2, t}-161.470 Y_{3, t}$ shows a clear mean reversion property over the sample period, indicating a stationary $I(0)$ variable over the sample period.

The implied significantly estimates of the parameters of interest are $\widehat{\eta}=-0.0062$ and $\widehat{\varepsilon}=-0.781$, which are both consistent with case $(c)$ of (8). The negative estimates of $\eta$ imply that OPEC supply costs depend positively on oil reserves, such that accumulated production decreases supply costs. Hence, we find support for Arrow (1962) learning by doing hypothesis. Also, the estimate of the inverse price elasticity, $\varepsilon$, is well within its interval of having a plausible economic interpretation. To sum up, our findings support the hypothesis of imperfect competition in the crude oil market where OPEC has some market power.

We can now illustrate how the estimates of $\varepsilon$ are consistent with the dominant producer model. It follows from the discussion in Sect. 2 that $\widehat{e}_{O P E C}=-1.28$ on average over the sample period when $\widehat{\varepsilon}=-0.781$. Since $\widehat{e}_{O P E C}<-1$, OPEC operates on the elastic part of its demand curve and $\widehat{\varepsilon}$ can in this sense be said to accommodate the dominant producer model. Using (10) and assuming $s=0.2$ and 
$M S O P E C=0.41$, which is the average over the sample period, we calibrate the price elasticity of world oil demand, $e_{W}$, to be $-0.41 .{ }^{10}$ We see from Fig. 3 that $\widehat{\varepsilon} \in\{-0.71,-0.84\}$ when $e_{W}=-0.41, s=0.2$ and MSOPEC is allowed to vary over the sample period. Similarly, $\widehat{e}_{W} \in\{-0.36,-0.45\}$ when $\widehat{\varepsilon}=-0.781$ and $s=0.2$. As pointed out by Golombek et al. (2018), who estimate the price elasticity of world oil demand to be -0.35 , a comparison of existing estimates of $e_{W}$ in the literature is difficult because these estimates are based on different data, sample periods and estimation methods. Nevertheless, the estimates in Dahl and Yücel (1991), Alhajji and Huettner (2000a), Gately and Huntington (2002), Cooper (2003) and Dees et al. (2007) range from -0.3 to -0.6 . Our estimates of $e_{W}$ are thus well within this interval.

We end this section by asking if the evidence of dominant behaviour of OPEC is actually attributed to Saudi Arabia as the largest producer of crude oil among the member countries. There is no consensus in the literature on the role of Saudi Arabia within OPEC, see Alkhathlan et al. (2014). A typical result is to find no consistent pattern for the behaviour of Saudi Arabia within OPEC, as discussed in Smith (2005). In what can be characterised as normal years, production by Saudi Arabia follows quite closely production by OPEC as a whole, but in some periods the behaviour of Saudi Arabia has deviated significantly. In these periods, Saudi Arabia have acted as a swing producer compensating for cutbacks in production from other OPEC members to reach the agreed total quota. Two examples in our sample period are the Gulf war in 2003 when Saudi Arabia compensated for the drop in output from Kuwait and Iraq and again in 2011 due to the war in Libya. This difference in behaviour is made possible because Saudi Arabia has spare capacity for crude oil extraction which can quickly be mobilised to compensate for the drop in output by other OPEC members due to conflicts and political factors. Alkhathlan et al. (2014) find that Saudi Arabia exports also bear a disproportionate share of the burden in situations of output restrictions within OPEC. In our view, these features of Saudi Arabia behaviour are not easily reconciled within the model presented in this paper. Nevertheless, we shed light on the possibility that the evidence of dominant behaviour of OPEC is attributed to Saudi Arabia by estimating (9) by means of data for Saudi Arabia alone.

Figure 4 shows the data used for Saudi Arabia together with the data used for OPEC. The two mentioned periods in which Saudi Arabia acted as a swing producer are apparent in the upper panel. From the middle panel, it is evident that the OPEC reference basket oil price and the Saudi Arabia crude light oil price follow each other closely throughout the sample period. Much the same picture is seen from the lower panel with regard to the OPEC and the Saudi Arabia supply costs.

Applying the same partial VAR and the same estimation period, we find one significant cointegrating relationship between Saudi Arabia production and the two composite variables in (9), just as in the case for OPEC as a whole. We obtain the following unrestricted cointegrating vector (normalised on Saudi Arabia production)

$$
Y_{1, t}=\text { const } .+\underset{(1.365)}{6.506 Y_{2, t}}+\underset{(12.781)}{48.853 Y_{3, t}},
$$

\footnotetext{
10 Assuming that $s=0.1$ and $s=0.3$, the latter being in line with results in Golombek et al. (2018), the estimates of $e_{W}$ become -0.47 and -0.35 , respectively.
} 

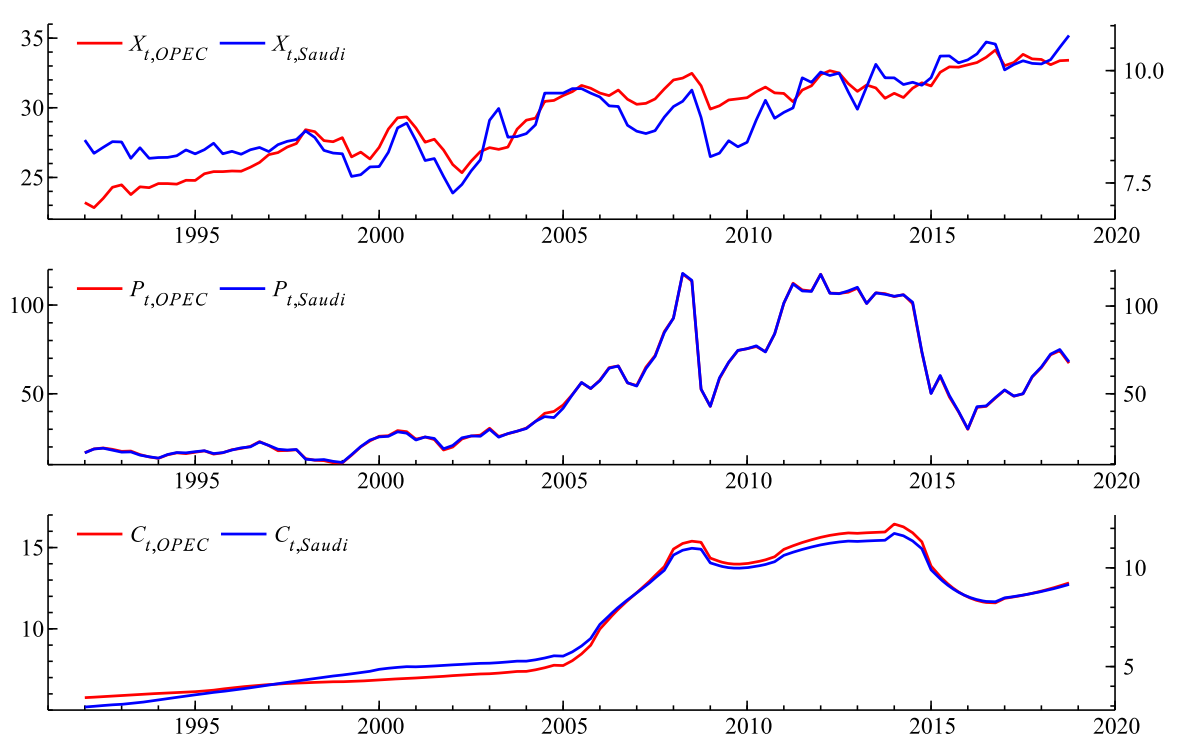

Fig. 4 Time series of OPEC and Saudi Arabia production $\left(X_{t, O P E C}, X_{t, \text { Saudi }}\right)$, OPEC reference basket oil price and Saudi Arabia crude light oil price $\left(P_{t, O P E C}, P_{t, S a u d i}\right)$ and OPEC and Saudi Arabia supply costs $\left(C_{t}\right.$, OPEC,$\left.C_{t, \text { Saudi }}\right)$. Sample period: $1992 q 1-2018 q 4$. Data for Saudi Arabia are measured on the right hand side axis. See footnote 7 for definitions, constructions and sources of the time series

with estimated standard errors in parentheses. The associated vector of adjustment coefficients is $\widehat{\alpha}=(-0.051,0.103)^{\prime}$ with corresponding $t$-values equal to -3.82 and 2.84 , respectively. The estimates of the parameters $\eta$ and $\varepsilon$ are thus significant and within sensible ranges. In particular, the estimated value of $\varepsilon$ is -0.87 compared to -0.78 in the case for OPEC as a whole. However, using (10), with MS Saudi $=0.125$, to calculate the implied value of the price elasticity for oil globally, we obtain implausible low (absolute) levels and even the wrong sign unless the assumed oil supply elasticity is very low $(s<0.16)$. If the supply elasticity of the fringe (which now includes also rest-OPEC) is zero, which definitely is a borderline case, the price elasticity of world oil demand becomes -0.14 . Thus, an improbably low supply elasticity produces a very low world oil demand elasticity according to our estimates of (9) using data for Saudi Arabia alone. These findings lead us to conclude that our model of output behaviour does not suit the case of Saudi Arabia well. On the other hand, the fact that Saudi Arabia is the largest producer within OPEC and has significant spare capacity enables Saudi Arabia to compensate for cutbacks in production by other member countries. In doing so, Saudi Arabia contributes in an important way to total OPEC production and OPEC behaviour as we model it in this paper.

\section{A dynamic model}

We now utilise the findings from the cointegration analysis and evaluate the empirical performance of an estimated CVAR model of OPEC behaviour in-sample. Our point 
of departure, following the modelling strategy in Harbo et al. (1998), is the general partial model written as

$$
\Delta\left(\begin{array}{l}
Y_{1, t} \\
Y_{2, t}
\end{array}\right)=\theta_{1} \Delta Y_{3, t}+\theta_{2} \Delta Y_{t-1}+\theta_{3} \Delta Y_{t-2}+\left(\begin{array}{c}
\alpha_{1} \\
\alpha_{2}
\end{array}\right) \widehat{e q c m}_{t-1}+\theta_{0}+\varepsilon_{t},
$$

where $\theta_{0}$ represents the constants, the seasonals $\left(S D_{1 t}, S D_{2 t}\right.$ and $\left.S D_{3 t}\right)$ and the impulse dummy for the financial crisis $(D 08 q 4)$. Note that (14) is balanced in the terminology of Banerjee et al. (1993, p. 166) when $Y_{1, t}, Y_{2, t}$ and $Y_{3, t}$ all are nonstationary $I(1)$ variables and when $\widehat{e q c m}_{t}$ is a stationary $I(0)$ variable, as verified in Sect. 4. Accordingly, (14) is amenable to standard estimation an inference techniques. We estimate (14) by full information maximum likelihood (FIML) and find that the resulting model has well-behaved residuals according to standard system diagnostic tests. A parsimonious model is then found by stepwise exclusion of insignificant variables in the general system one by one, relying on the Sargan test for overidentifying restrictions. We obtain the following parsimonious model together with estimated standards errors of coefficients (in parenthesis), system diagnostic tests ${ }^{11}$ and the Sargan test:

$$
\begin{aligned}
& \Delta \widehat{Y}_{1, t}=\underset{(0.104)}{0.302} \Delta Y_{1, t-1}-\underset{(0.099)}{0.151} \Delta Y_{1, t-2}-\underset{(0.118)}{0.181} \Delta Y_{2, t-1}-\underset{(0.087)}{0.216} \Delta Y_{2, t-2} \\
& \underset{(0.004)}{-0.018 \widehat{e q c m}_{t-1}}-\underset{(0.60)}{2.33}+\underset{(0.13)}{0.27 S D_{1 t}}+\underset{(0.13)}{0.43 S D_{3 t}}-\underset{(0.49)}{0.85} \mathrm{D} 08 q 4 \\
& \Delta \widehat{Y}_{2, t}=\underset{(0.072)}{-0.171} \Delta Y_{2, t-2} \underset{(0.961)}{-5.369} \Delta Y_{3, t} \underset{(0.952)}{-2.211} \Delta Y_{3, t-1} \\
& +\underset{(0.003)}{0.024 \widehat{e q c m}_{t-1}}+\underset{(0.36)}{3.36}-\underset{(0.45)}{4.08 D 08 q 4} \\
& \text { FIML, } T=88(1992 q 1-2013 q 4) \\
& \text { Vector } A R_{1-5}: F(20,140)=1.22[0.25] \\
& \text { VectorNORM: } \chi^{2}(4)=6.02[0.20] \\
& \text { Vector HET: } F(57,197)=1.51[0.02] \\
& \text { Sargan test: } \chi^{2}(11)=6.32[0.85]
\end{aligned}
$$

The diagnostics indicate that (15) is quite well specified. The Sargan test supports the restrictions imposed on the model, and the variables are significant at conventional levels. OPEC production seems to be rather persistent as represented by the significant autoregressive coefficients of $\Delta Y_{1, t-1}$ and $\Delta Y_{1, t-2}$. The $\widehat{e q c m}_{t-1}$ appears with a $t$ value of -4.5 in the specification for $\Delta Y_{1, t}$, hence adding force to the results obtained from the cointegration analysis. We do not find any short-run effects on $Y_{1, t}$ from $Y_{3, t}$, only lagged short-run effects from $Y_{2, t}$. This empirical feature of the model tells us that OPEC output is not affected by the oil price or the production costs in the current quarter. No contemporaneous short-run effects and the relatively small magnitude of the estimated adjustment coefficient of -0.018 together imply rather slow adjustment in OPEC production.

\footnotetext{
11 See Doornik and Hendry (2009, p. 172). The numbers in square brackets are $p$-values.
} 

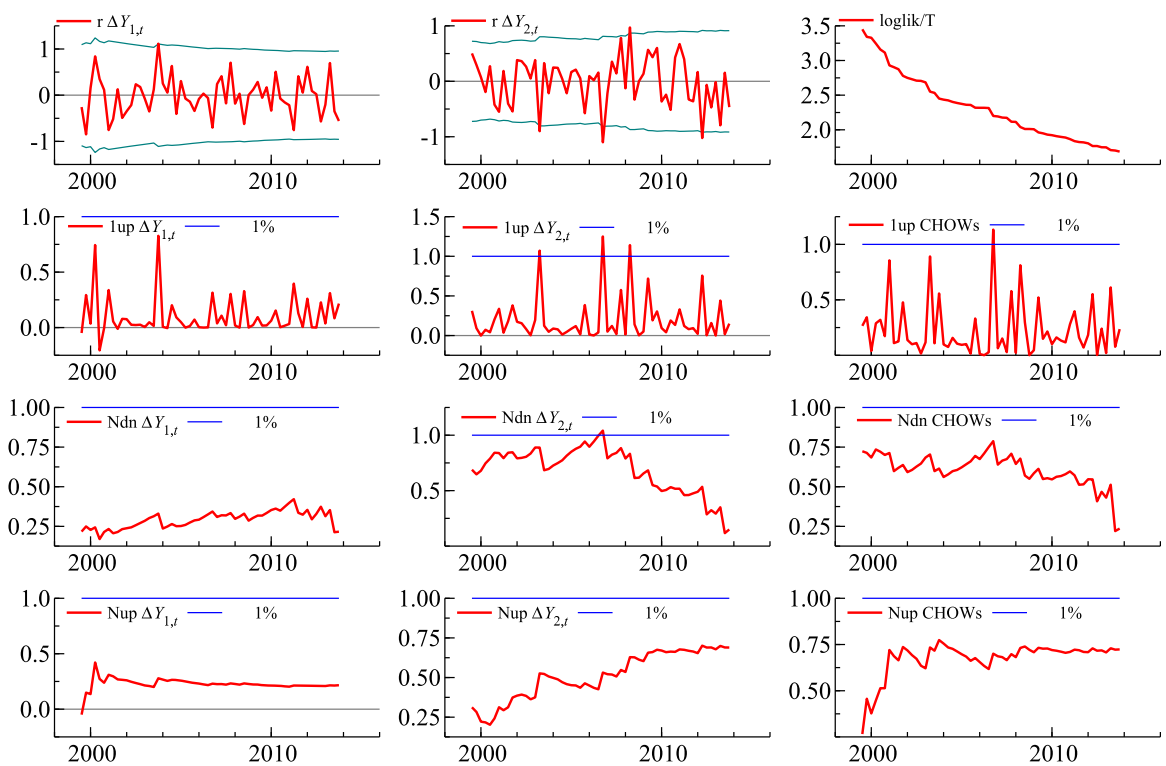

Fig. 5 Recursive statistics* of (15). Sample period: 1992q1-2013q4. * See Doornik and Hendry (2009, p. 75)

The specification for $\Delta Y_{2, t}$ shows that $Y_{2, t}$ also equilibrium corrects when OPEC production deviates from its optimal level given by (9). The equilibrium correction term includes both crude oil prices and OPEC production costs. When OPEC supply is not in line with (9), the oil price will change according to the demand function in (1). Furthermore, output will affect OPEC costs according to the oil reserves condition in (2) and the cost function in (3), which combined relate OPEC costs to accumulated output. So, the system in (15) basically tells us that the simultaneity of OPEC output and the price-cost ratio $(P / C)$ inherent in the theoretical model is empirically relevant. That is why a FIML approach and not a single equation approach is preferable in our case. Finally, we find some contemporaneous and lagged effects of $Y_{3, t}$ on $Y_{2, t}$ and large negative effects from the impulse dummy $D 08 q 4$ due to the aforementioned huge drop in the oil price during the financial crisis.

We use recursive methods to investigate whether (15) exhibits empirical constancy in-sample. Figure 5 depicts the recursive residuals with $\pm 2 \hat{\sigma}_{t}$ and the scaled loglikelihood function as $T$ increases (i.e. the recursively computed Sargan test) in the first row, the sequence of one step Chow tests in the second row, the sequence of break point Chow tests in the third row and the sequence of forecast Chow tests in the fourth row, all of which are scaled by their 1 per cent critical values; see Doornik and Hendry (2009, p. 75). We see from the recursive residuals and the one step Chow tests that there are some minor instabilities in the specification for $Y_{2, t}$ in 2007/2008 during the financial crisis. That said, there is no clear evidence of instabilities in the specification for $Y_{1, t}$ and the system as a whole. We therefore conclude that the OPEC behaviour based on (15) has not changed significantly in-sample. 


\section{Forecasting exercise}

We make use of dynamic forecasts to evaluate the empirical performance of the estimated dynamic model out-of-sample, with a special focus on any forecasting failure around the November 2014 meeting. Because dynamic forecasts are ex ante and based on reuse of forecasts from previous periods, we need to take account of the lag structure of the estimated model in order to do dynamic forecasting. To illustrate referring to Doornik and Hendry (2009, p. 153), consider a simple autoregressive distributed lag model of the form

$$
y_{t}=\varphi_{1} y_{t-1}+\varphi_{2} z_{t}+\epsilon_{t}
$$

where $y_{t}$ is estimated over $t=1, \ldots, T, z_{t}$ is a non-modelled variable, and $\epsilon_{t} \sim$ i.i.d.N $\left(0, \sigma^{2}\right)$. Using backward substitution for any $h$ in the forecast period $h=$ $1, \ldots, H$ commencing at $T$, we obtain

$$
y_{T+h}=\varphi_{1}^{h} y_{T}+\sum_{i=0}^{h-1} \varphi_{1}^{i} \varphi_{2} z_{T+h-i}+\sum_{i=0}^{h-1} \varphi_{1}^{i} \epsilon_{T+h-i} .
$$

Letting $\hat{y}_{T+h, h}$ denote the $h$-steps dynamic forecast made for period $T+h$, we have

$$
\hat{y}_{T+h, h}=\hat{\varphi}_{1}^{h} y_{T}+\sum_{i=0}^{h-1} \hat{\varphi}_{1}^{i} \hat{\varphi}_{2} z_{T+h-i}
$$

which clearly shows that dynamic forecasts, as opposed to one-step forecasts, do not use actual values for lagged $y$ beyond $T$ to form the forecasts. Using (17) and (18), the forecast error, $e_{T+h, h}=y_{T+h}-\hat{y}_{T+h, h}$, becomes

$$
e_{T+h, h}=\left(\varphi_{1}^{h}-\hat{\varphi}_{1}^{h}\right) y_{T}+\sum_{i=0}^{h-1}\left(\varphi_{1}^{i} \varphi_{2}-\hat{\varphi}_{1}^{i} \hat{\varphi}_{2}\right) z_{T+h-i}+\sum_{i=0}^{h-1} \varphi_{1}^{i} \epsilon_{T+h-i}
$$

When the parameter uncertainty can be ignored, as we shall do in our forecasting exercise, the forecast error simplifies to ${ }^{12}$

$$
e_{T+h, h}=\sum_{i=0}^{h-1} \varphi_{1}^{i} \epsilon_{T+h-i}
$$

As previously mentioned, we employ twenty quarters (2014q1-2018q4) for out-ofsample observations, including the November 2014 meeting, in order to form dynamic forecasts in the manner outlined above. Figure 6 depicts actual values of $Y_{1, t}$ together with dynamic forecasts based on (15), adding bands of 95 per cent confidence intervals

\footnotetext{
12 See Doornik and Hendry (2009, p. 155) for how parameter uncertainty can be taken into account in forming dynamic forecasts.
} 


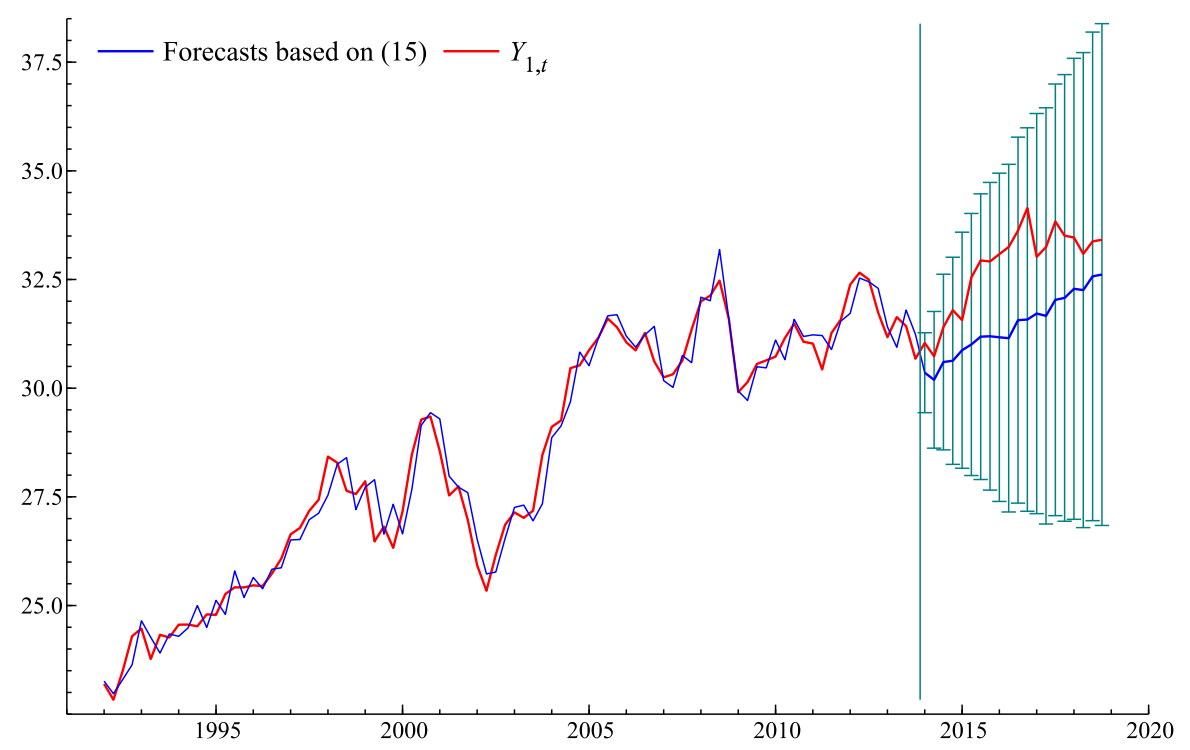

Fig. 6 Actual values and dynamic forecasts* of $Y_{1, t} \pm 2 \hat{\sigma}_{t}$. In-sample: $1992 q 1-2013 q 4$, out-of-sample: $2014 q 1-2018 q 4$. Parameter uncertainty is not taken into account in forming the forecasts. * See Doornik and Hendry (2009, p. 153)

to each forecast. Generally, the out-of-sample forecasting performance is quite poor. Although the actual values of $Y_{1, t}$ all stay within their corresponding confidence intervals, we see that (15) systematically underpredicts OPEC production over the forecast period. ${ }^{13}$ At the end of 2016, the model underpredicts $Y_{1, t}$ by as much as 2.5 million barrels per day. During 2018, however, the model forecasts OPEC production quite well, which may not be surprising given the fact that OPEC and other oil producing countries, including Russia, in November 2016 agreed on a plan starting in 2017 to reduce production.

Using a sequence of parameter constancy forecast Chow tests, we can detect whether there are any significant structural breaks in the forecast period; see Doornik and Hendry (2009, p. 36). We find that these test statistics based on (15) are far from being significant for the first three quarters of 2014. However, from the fourth quarter of 2014 to the first quarter of 2017 , these test statistics are overall significant at the 5 per cent significance level. Then, from the second quarter of 2017 to the end of the forecast period no significant structural breaks are detected. Because a significant structural break is detected around the fourth quarter of 2014, we conclude that OPEC did indeed change behaviour after the November 2014 meeting. Behar and Ritz (2016) also conclude, using a calibrated equilibrium model of the oil market, that OPEC changed behaviour from an accommodation strategy up to 2014 to a market share strategy thereafter.

13 The RMSE (root-mean-square error) equals 1.47 and is given by $\left[\frac{1}{H} \sum_{t=1}^{H}\left(Y_{1, t}-\hat{Y}_{1, t}\right)^{2}\right]^{1 / 2}$, where $H=20$ and $Y_{1, t}$ and $\hat{Y}_{1, t}$ are the actual values of and the forecasts for OPEC production, respectively. 


\section{Conclusions}

In this paper, we have formulated a theoretical model of OPEC behaviour that encompasses a number of hypotheses discussed in the literature, among them price taking behaviour and imperfect competition in various forms. By confronting the theoretical model with quarterly data for the period from 1992 to 2013 within the context of a CVAR model, we found support for the imperfect competition hypothesis regarding the supply decisions of OPEC. Our implied average estimate of the price elasticity of demand for OPEC oil is less than minus unity, consistent with the dominant producer model. Besides, we found that costs of extraction are significantly affected by the resource stock through learning by doing effects in OPEC production.

We have also shown that a dynamic equilibrium correction model exhibits constancy in-sample. A forecasting exercise for the period from 2014 to 2018 revealed, however, that the model systematically underpredicts OPEC production and by as much as 2.5 million barrels per day at the end of 2016. We have also found evidence of a significant structural break around the fourth quarter of 2014, which coincides with the November 2014 meeting. During 2018, however, the model forecasts OPEC production quite well. Our findings suggest that the behaviour of OPEC did indeed change significantly after the November 2014 meeting, presumably to limit the role of competitors like American producers of shale oil.

That said, we emphasise that the theoretical model for estimation purposes in this paper is basically related to the supply behaviour of OPEC. While important, the demand side of the oil market, that is the residual demand facing OPEC, is not an explicit part of the empirical model. The question of whether this untested simplifying assumption is crucial to the conclusions of the empirical analyses is left for future research.

Acknowledgements We are grateful to Knut Einar Rosendahl, Terje Skjerpen, Anders Rygh Swensen and two anonymous referees for helpful comments and suggestions on earlier drafts. We are also indebted to Lars Lindholt for providing us with the data of supply costs of OPEC and Saudi Arabia used in Hansen and Lindholt (2008). The econometric modelling in this paper is carried out with PcGive 14; see Doornik and Hendry (2013). The usual disclaimer applies.

Funding Open access funding provided by Statistics Norway.

\section{Declarations}

Conflict of interest The authors declare that they have no conflict of interest.

Ethical approval This article does not contain any studies with human participants or animals performed by the authors.

Open Access This article is licensed under a Creative Commons Attribution 4.0 International License, which permits use, sharing, adaptation, distribution and reproduction in any medium or format, as long as you give appropriate credit to the original author(s) and the source, provide a link to the Creative Commons licence, and indicate if changes were made. The images or other third party material in this article are included in the article's Creative Commons licence, unless indicated otherwise in a credit line to the material. If material is not included in the article's Creative Commons licence and your intended use is not permitted 
by statutory regulation or exceeds the permitted use, you will need to obtain permission directly from the copyright holder. To view a copy of this licence, visit http://creativecommons.org/licenses/by/4.0/.

\section{References}

Alhajji AF, Huettner D (2000a) OPEC and world crude oil markets from 1973 to 1994: cartel, oligopoly, or competitive? Energy J 21:31-60

Alhajji AF, Huettner D (2000b) OPEC and other commodity cartels: a comparison. Energy Policy 28:11511164

Alkhathlan K, Gately D, Javid M (2014) Analysis of Saudi Arabia's behavior within OPEC and the world oil market. Energy Policy 64:209-225

Almoguera PA, Douglas CC, Herrera AM (2011) Testing for the cartel in OPEC: non-cooperative collusion or just non-cooperative? Oxf Rev Econ Policy 27:144-168

Arrow KJ (1962) The economic implications of learning by doing. Rev Econ Stud 29:155-173

Banerjee A, Dolado J, Galbraith JW, Hendry DF (1993) Co-integration, error correction, and the econometric analysis of non-stationary data. Oxford University Press, New York

Behar A, Ritz RA (2016) An analysis of OPEC's strategic actions, US shale growth and the 2014 oil price crash, IMF working paper 16/131, International Monetary Fund

Berg E, Kverndokk S, Rosendahl KE (1997) Market power, international $\mathrm{CO}_{2}$ taxation and oil wealth. Energy J 18:172-210

Bckem S (2004) Cartel formation and oligopoly structure: a new assessment of the crude oil market. Appl Econ 36:1355-1369

Boug P, Cappelen Å, Swensen AR (2016) Modelling OPEC behaviour: theory and evidence, Discussion Papers 843, Statistics Norway

Cooper JCB (2003) Price elasticity of demand for crude oil: estimates for 23 countries. OPEC Rev 27:1-8

Dahl C, Yücel M (1991) Testing alternative hypotheses of oil producer behavior. Energy J 12:117-138

Dees S, Karadeloglu P, Kaufmann RK, Sanchez M (2007) Modelling the world oil market: assessment of a quarterly econometric model. Energy Policy 35:179-191

Devarajan S, Fisher AC (1981) Hotelling's ‘Economics of Exhaustible Resources': fifty years later. J Econ Literat 19:65-73

Doornik JA, Hendry DF (2013) Modelling dynamic systems using PcGive 14: vol II. Timberlake Consultants Ltd, London

Doornik JA, Hendry DF(2009) Modelling dynamic systems using PcGive Volume I and II, Timberlake Consultants Ltd, London

Fattouh B, Mahadeva L (2013) OPEC: what difference has it made? Ann Rev Resour Econ 5:427-443

Gately D, Huntington HG (2002) The asymmetric effects of changes in price and income on energy and oil demand. Energy J 23:9-55

Golombek R, Irarrazabal AA, Ma L (2018) OPEC's market power: an empirical dominant firm model for the oil market. Energy Econ 70:98-115

Griffin JM (1985) OPEC behavior: a test of alternative hypotheses. Am Econ Rev 75:954-963

Hansen PV, Lindholt L (2008) The market power of OPEC 1973-2001. Appl Econ 40:2939-2959

Harbo I, Johansen S, Nielsen B, Rahbek A (1998) Asymptotic inference of cointegrating rank in partial systems. J Bus Econ Stat 16:388-399

Hotelling H (1931) The economics of exhaustible resources. J Polit Econ 39:137-175

Johansen S (1995) Likelihood-based inference in cointegrated vector autoregressive models. Oxford University Press, New York

Juselius K (2006) The cointegrated VAR model: methodology and applications. Oxford University Press, New York

Juselius K (2015) Haavelmo's probability approach and the cointegrated VAR. Econ Theory 31:213-232

Juselius K (2019) The cointegrated VAR methodology. Economics and Finance, Oxford University Press USA, Oxford Research Encyclopedia, pp 1-25

Kaufmann RK, Bradford A, Belanger LH, Mclaughlin JP, Miki Y (2008) Determinants of OPEC production: implications for OPEC behavior. Energy Econ 30:333-351

Nakov A, Nuño G (2013) Saudi Arabia and the oil market. Econ J 123:1333-1362

Okullo SJ, Reynès F (2016) Imperfect cartelization in OPEC. Energy Econ 60:333-344 
Smith JL (2009) World oil: market or mayhem? J Econ Perspect 23:145-164

Smith JL (2005) Inscrutable OPEC? Behavioral tests of the cartel hypothesis. Energy J 26:51-82

Spilimbergo A (2001) Testing the hypothesis of collusive behavior among OPEC members. Energy J 23:339-353

Publisher's Note Springer Nature remains neutral with regard to jurisdictional claims in published maps and institutional affiliations. 